\title{
First report of leaf blight on peanut caused by Nigrospora sphaerica in China
}

\author{
Xiaoyu Liu ${ }^{1}$ (D) Fengyu $\mathrm{Yu}^{1} \cdot$ Dengqiang Fu ${ }^{1}$ - Weibo Yang ${ }^{1}$ \\ Received: 24 December 2019 / Accepted: 1 April 2020 / Published online: 20 April 2020 \\ (C) Società Italiana di Patologia Vegetale (S.I.Pa.V.) 2020
}

Keywords Nigrospora sphaerica $\cdot$ Leaf blight on peanut $\cdot$ China

Nigrospora sphaerica (Sacc.) E.W. Mason is a seriously damaging pathogen causing leaf blight on a few plant species. In July 2018, a leaf blight of unknown etiology was observed on peanut (Arachis hypogaea Linn.) leaves in Wenchang, China. Initial symptoms included circular brown spots, $2 \mathrm{~mm}$ in diameter, surrounded by yellow haloes, gradually developing into circular or elliptical necroses of up to $6 \mathrm{~mm}$ in diameter. Symptomatic tissues were surface-sterilized with $70 \%$ ethanol for $30 \mathrm{~s}$ and $0.1 \% \mathrm{HgCl}_{2}$ for $60 \mathrm{~s}$, washed three times in sterile water and put on PDA at $25^{\circ} \mathrm{C}$. After 5 days at $25 \pm 2{ }^{\circ} \mathrm{C}$, the fungus developed flat, white and light-to-dark grey colonies, with white-to-dark brown septate branched hyphae. Conidia typical for Nigrospora were black, one-celled (10.2$14.6 \mu \mathrm{m}$ ), and borne singly at the tips of conidiophores. The internal transcribed spacer (ITS) region of the rDNA was sequenced using ITS1/ITS4 primers and accession No. MK482388 was $99 \%$ identical to N. sphaerica accession Nos. MG669225.1 and HQ608063.1. For pathogenicity testing, a conidial suspension $\left(10^{6}\right.$ conidia $\left.\mathrm{ml}^{-1}\right)$ from a 7-day-old culture of $N$. sphaerica was used to inoculate ten leaves of yue-you 7 peanut cultivar, followed by incubation in a controlled environment chamber at $25^{\circ} \mathrm{C}$ with $70-80 \%$ humidity. As a control, ten leaves of yue-you 7 peanut cultivar were inoculated with sterile distilled water. Two weeks after inoculation, symptoms were observed only on the leaves inoculated with conidia and the fungus was consistently re-isolated. Nigrospora sphaerica was observed on blueberry in Argentina, sugarcane in China, and tea in India (Cui et al. 2018; Dutta et al. 2015). To our knowledge, this is the first report of $N$. sphaerica on peanut.

Acknowledgments This study was supported by the Key Research and Development Project in Hainan Province (ZDYF2018100).

\section{References}

Cui YP, Peng AT, Wu B, Lin JF, Song XB, Li ZL (2018) First report of Nigrospora leaf blight on sugarcane caused by Nigrospora sphaerica in China. Plant Dis 102(4):824. https://doi.org/10.1094/ PDIS-07-17-1060-PDN

Dutta J, Gupta S, Thakur D, Handique PJ (2015) First report of Nigrospora leaf blight on tea caused by Nigrospora sphaerica in India. Plant Dis 99(3):417. https://doi.org/10.1094/PDIS-02-140196-PDN

Publisher's note Springer Nature remains neutral with regard to jurisdictional claims in published maps and institutional affiliations.
Xiaoyu Liu

liuxiaoyu06120210@163.com

Coconut Research Institute of Chinese Academy of Tropical Agricultural Sciences/ Hainan Peanut Research Station Of National Peanut Engineering Technology Research Center,

Wenchang 571339, China 